\title{
JOTSE'S EVOLUTION
}

\section{Beatriz Amante García ${ }^{1}$ (D), María Martínez Martínez ${ }^{2}$ D}

${ }^{1}$ Projectes d'Enginyeria, Universitat Politècnica de Catalunya (Spain)

${ }^{2}$ Enginyeria Química, Universitat Politècnica de Catalunya (Spain)

beatriz.amante@upc.edu,rosario.martinez@upc.edu

We present the first editorial of the year in JOTSE. As usual, this first editorial presents an analysis of our Journal evolution. In this sense, we reflect on the changes just undergone in 2020 with an international pandemic "covid-19" and the challenges to be faced in the New Year 2021.

As we can observe in Figure 1, the objective of steady growth has been accomplished throughout these 10 last years, even with this terrible pandemic.

\section{Papers received/year in JOTSE website}

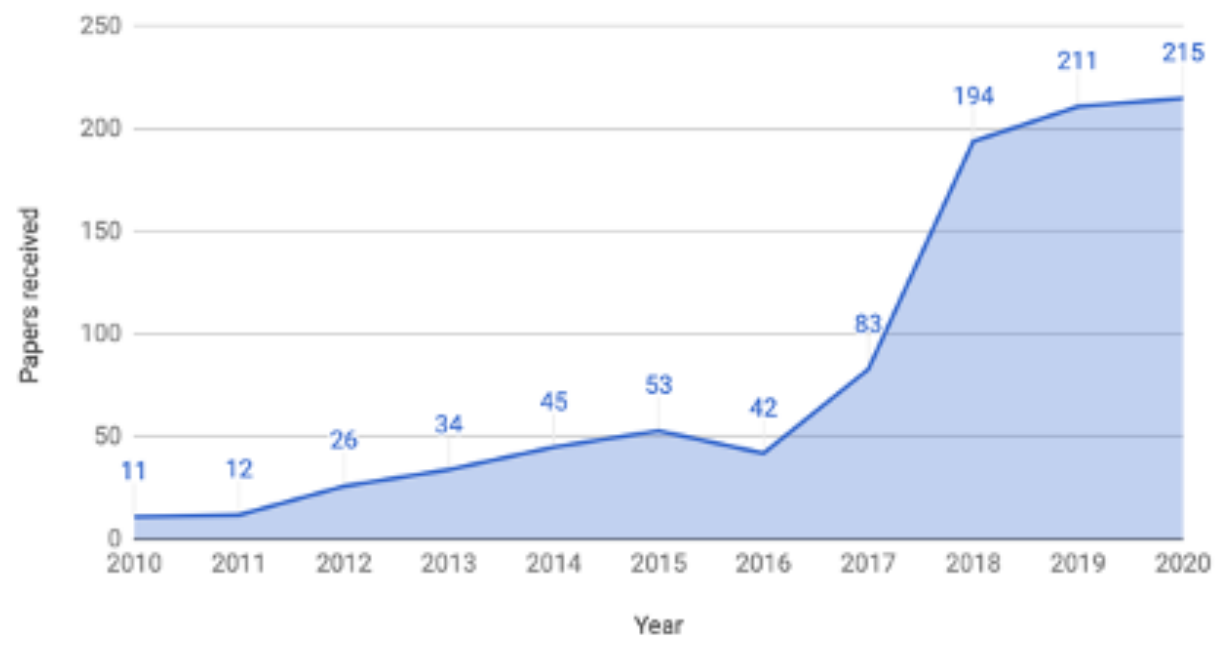

Figure 1. JOTSE's evolution

As a matter of fact, if we observe JOTSE's monthly evolution we can state that March, July, November and December are the months with more papers submissions as the average increases (as shown in Table 1) In particular, in year 2020 we have had $2 \%$ as much articles than in preceding year despite the difficulties due to the pandemic COVID-19. 


\begin{tabular}{|c|c|c|c|c|c|c|c|c|c|c|c|}
\hline & $\mathbf{2 0 1 0}$ & $\mathbf{2 0 1 1}$ & $\mathbf{2 0 1 2}$ & $\mathbf{2 0 1 3}$ & $\mathbf{2 0 1 4}$ & $\mathbf{2 0 1 5}$ & $\mathbf{2 0 1 6}$ & $\mathbf{2 0 1 7}$ & $\mathbf{2 0 1 8}$ & $\mathbf{2 0 1 9}$ & $\mathbf{2 0 2 0}$ \\
\hline January & & 0 & 2 & 1 & 9 & 4 & 3 & 2 & 12 & 26 & 13 \\
\hline February & & 1 & 4 & 1 & 0 & 4 & 1 & 7 & 27 & 15 & 10 \\
\hline March & & 0 & 1 & 2 & 3 & 5 & 1 & 4 & 11 & 27 & 21 \\
\hline April & 1 & 1 & 0 & 3 & 2 & 2 & 2 & 0 & 10 & 12 & 17 \\
\hline May & 3 & 2 & 0 & 0 & 2 & 2 & 3 & 5 & 24 & 13 & 16 \\
\hline June & 1 & 4 & 0 & 3 & 1 & 4 & 3 & 3 & 11 & 8 & 17 \\
\hline July & 1 & 0 & 7 & 5 & 8 & 5 & 3 & 2 & 13 & 15 & 22 \\
\hline August & 1 & 1 & 1 & 2 & 1 & 2 & 2 & 13 & 9 & 12 & 17 \\
\hline September & 0 & 1 & 3 & 1 & 5 & 5 & 2 & 14 & 32 & 24 & 18 \\
\hline October & 2 & 0 & 4 & 1 & 1 & 3 & 8 & 8 & 8 & 25 & 16 \\
\hline November & 1 & 1 & 1 & 6 & 2 & 9 & 11 & 11 & 16 & 14 & 26 \\
\hline December & 1 & 1 & 3 & 9 & 11 & 8 & 3 & 14 & 21 & 20 & 22 \\
\hline TOTAL & $\mathbf{1 1}$ & $\mathbf{1 2}$ & $\mathbf{2 6}$ & $\mathbf{3 4}$ & $\mathbf{4 5}$ & $\mathbf{5 3}$ & $\mathbf{4 2}$ & $\mathbf{8 3}$ & $\mathbf{1 9 4}$ & $\mathbf{2 1 1}$ & $\mathbf{2 1 5}$ \\
\hline
\end{tabular}

Table 1. Article submissions evolution from 2010 to 2020

\begin{tabular}{|l|l|c|c|c|}
\hline & Issues & $\begin{array}{c}\text { Articles published in } \\
\text { regular issue }\end{array}$ & $\begin{array}{c}\text { Articles published in } \\
\text { special issue }\end{array}$ & $\begin{array}{c}\text { Total } \\
\text { papers }\end{array}$ \\
\hline $\mathbf{2 0 1 1}$ & $2(2+0)$ & 11 & 0 & 11 \\
\hline $\mathbf{2 0 1 2}$ & $2(2+0)$ & 12 & 0 & 12 \\
\hline $\mathbf{2 0 1 3}$ & $3(2+1)$ & 11 & 7 & 18 \\
\hline $\mathbf{2 0 1 4}$ & $4(2+2)$ & 12 & 14 & 26 \\
\hline $\mathbf{2 0 1 5}$ & $4(2+2)$ & 10 & 15 & 25 \\
\hline $\mathbf{2 0 1 6}$ & $3(2+1)$ & 13 & 6 & 19 \\
\hline $\mathbf{2 0 1 7}$ & $3(2+1)$ & 10 & 11 & 21 \\
\hline $\mathbf{2 0 1 8}$ & $4(2+2)$ & 26 & 10 & 36 \\
\hline $\mathbf{2 0 1 9}$ & $3(2+1)$ & 29 & 11 & 40 \\
\hline $\mathbf{2 0 2 0}$ & $2(2+0=$ & 23 & 0 & 23 \\
\hline
\end{tabular}

Table 2. Articles published evolution from 2010 to 2020

As to the articles published (included in Table 2), we can observe the evolution of the volumes/issues and articles published in the years (2011-2020). In 20120, we have not published special issues and therefore we have reduced a little bit the number of articles published.

When analysing the percentage of rejected articles, we can see in the website of JOTSE that in year 2016 it was $36 \%$, in 2017 the figure rose up to $69 \%$, in 2018 it was 64\%, in 2019 it was $63 \%$ and in 2020 it was $49 \%$ (a little less than before). Although if we have a look in more detail at the numbers, of 216 received, only 49 go through the review process and of these halves are rejected.

These numbers show the rigor of the work developed by the journal team. It is important to mention here the role of JOTSE's editorial team and reviewers who do their job with much quality and out of their generosity. In fact, we could not publish our journal without their help and, therefore, we thank them all to be here, especially this complicated pandemic year.

Now, if we analyse JOTSE's internationalisation as to visits to its website is concerned (one of our challenges). The countries that have visited JOTSE's website more frequently in the last years and more particularly in 2020 were:

-Philippines the first position with 28\% of visited JOTSE's website (82.935 number of visits in 2020). 
-United States was second with $15.3 \%$.

-Indonesia with $8.4 \%$ and Spain with $8.3 \%$ are in the third and fourth position.

This is a clear evidence that the degree of internationalisation of JOTSE Journal is keeping. At the moment we have more authors from foreign countries (46 last year) Only 28 authors are from Spain (this is a $38 \%$ ).

Finally, we repeat the importance of the reviewers and the JOTSE's editorial team without their help we could not publish at all this journal.

To conclude, the new objectives is to continue extending and reaching more countries, growing moderately and with quality.

Last but not least, we would like to thank to readers and authors for continuing to trust us.

\section{Declaration of Conflicting Interests}

The authors declared no potential conflicts of interest with respect to the research, authorship, and/or publication of this article.

\section{Funding}

The authors received no financial support for the research, authorship, and/or publication of this article.

\section{To cite this article:}

Amante García, B., \& Martínez Martínez, M (2021). JOTSE’s Evolution. Journal of Technology and Science Education, 11(1), 1-3. https://doi.org/10.3926/jotse.1238

Published by OmniaScience (www.omniascience.com)

Journal of Technology and Science Education, 2021 (www.jotse.org)

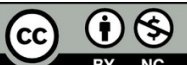

Article's contents are provided on an Attribution-Non Commercial 4.0 Creative commons International License. Readers are allowed to copy, distribute and communicate article's contents, provided the author's and JOTSE journal's names are included. It must not be used for commercial purposes. To see the complete licence contents, please visit https://creativecommons.org/licenses/by-nc/4.0/. 